J.N.M. Agricola*, J.L. Top and A.F. Fort Department of Physics, University of Zambia P.0. Box 32379, Lusaka

Abstract High Gradient Magnetic Separation of small (5-38 $\mu \mathrm{m})$ weakly magnetic copper mineral particles from a copper concentrate and ore has been performed. In previous work coarser fractions of these minerals, bornite and chalcopyrite, were separated successfully. The recovery of the smaller particles in the magnetic fraction decreases but their grade increases compared to the results obtained on the larger particles. At a magnetic background field of $1.3 \mathrm{~T}$ the concentrate was upgraded from $72 \%$ bornite and chalcopyrite to $86 \%$ with a recovery of $82 \%$ and the ore from $16 \%$ magnetic minerals to $44 \%$ with a recovery of $72 \%$.

\title{
INTRODUCTION
}

In Zambia there is a growing interest in the search of new concentration techniques of copper minerals from poor ores and tailings. The most important copper minerals, bornite and chalcopyrite, are both weakly magnetic. Magnetic separation has already been performed on two particle size fractions i.e. 53-75 $\mu \mathrm{m}$ and 38-53 $\mu \mathrm{m}$ of varous copper samples ${ }^{1}$. Presently magnetic separation was applied to a smaller particle size fraction i.e. 5-38 $\mu \mathrm{m}$ of a copper concentrate and ore sample. The minerals that are present in these samples are listed in Table 1. In addition to their chemical composition and average magnetic mass susceptibility their weight distribution, determined by ore microscopy, in both samples is also given.

TABLE 1

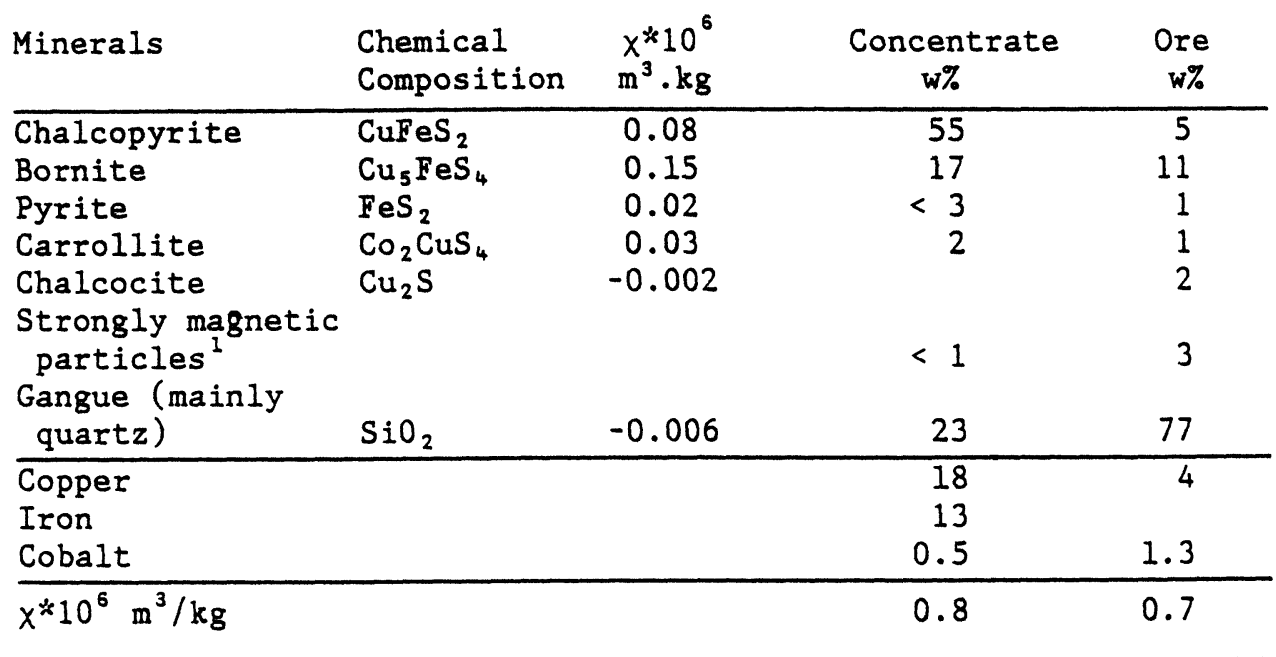


The second part of Table 1 contains the copper, iron and cobalt content measured by atomic absorption spectrosocopy and the magnetic susceptibility measured with a mutual inductance bridge. The major contribution to the susceptibility of the samples arises from the strongly magnetic particles, which contain mainly pyrrhotite and some hematite and magnetite.

\section{MAGNETIC SEPARATION}

The magnetic separation was performed with an in-house built 1.3 T transverse High Gradient Magnetic Separator. An oblong canister $23 \times 32 \times 104 \mathrm{~mm}$ filled with $5 \%$ steelwool of filament diameter 50-100 um (supplied by Frantz Co.) was used. Only 55\% of the filter volume was within the field of the circular pcies of a horseshoe magnet, so that the effective volume was $42 \mathrm{ml}$.

The samples were prepared from wet sieved fractions with particles smaller than $38 \mu \mathrm{m}$. Particles smaller than 5-10 $\mu \mathrm{m}$, depending on their specific gravity, were removed by elutriation.

In the magnetic separation process the slurry was fed downwards into the filter with an average flow velocity of $70 \mathrm{~mm} / \mathrm{s}$. Trapped nonmagnetic particles were flushed out with a flow velocity twice as high with the magnetic field still on. Magnetic particles were flushed out with much higher velocities at zero field. In both cases the flushing was done in both upward and downward directions until the effluent was clear.

Nonmagnetic particles that are recovered in the magnetic fraction arise from clogging and mechanical capture (together called mechanical trapping later on) of these particles in the matrix. This mechanical trapping was determined at zero field for different particle size fractions of the concentrate by measuring the amount of material that remained in the filter after the first flushing step. The results given in Table 2 show that the amount of mechanical trapping decreases for smaller particles. As the estimated size of the voids in the matrix is $250-500 \mu \mathrm{m}$ it can therefore be assumed that the mechanical trapping of coarser particles must be mainly due to clogging.

TABLE 2

\begin{tabular}{cc}
\hline $\begin{array}{c}\text { Particle size } \\
\text { fraction in } \mu \mathrm{m}\end{array}$ & $\begin{array}{l}\text { Mechanical } \\
\text { trapping in \% }\end{array}$ \\
\hline $53-75$ & 8 \\
$38-53$ & 6 \\
$5-38$ & 3 \\
\hline
\end{tabular}


The filter was saturated when about 38 of material was trapped under the used separation conditions. Therefore magnetic separation was applied to batches of $5 \mathrm{~g}$, which were mixed with 250 $\mathrm{ml}$ water.

In order to remove strongly magnetic particles before the maximum magnetic field was applied, magnetic separation was first performed at a lower fieldstrength of $0.5 \mathrm{~T}$. Thereafter each bath was treated twice at $1.3 \mathrm{~T}$.

\section{RESULTS}

The first magnetic separation was applied to a 5-38 $\mu \mathrm{m}$ fraction of the copper concentrate. Table 3 shows the obtained results. The reported grades and recoveries were determined from incident light microscopic analysis. This technique is less accurate for the size fraction considered due to the wide range of particle sizes. Further, the amount of gangue is undervalued. The grade and recovery of the copper and iron were obtained by atomic absorption spectroscopy. The grade and recovery of the weakly magnetic minerals, bornite and chalcopyrite, in the mags are $86 \%$ and $82 \%$ respectively, which is good. Also the recovery of the copper and iron in the mags is good in spite of its presence in the weaker ('non') magnetic minerals in the non-mags.

TABLE 3 Results Concentration

\begin{tabular}{lcccc}
\hline & \multicolumn{2}{c}{ MAGS $58 \%$ of feed } & \multicolumn{2}{c}{ NON MAGS $42 \%$ of feed } \\
\cline { 2 - 5 } Minerals & Grade\% & Recovery \% & Grade \% & Recovery \% \\
\hline Chalcopyrite & 63 & 80 & 22 & 20 \\
Bornite & 23 & 90 & 4 & 10 \\
Pyrite+Carrollite & 4 & 40 & 8 & 60 \\
Strong mags & $<1$ & 100 & & 83 \\
Gangue & 10 & 17 & 66 & 12 \\
\hline Copper & 27 & 88 & 5 & 14 \\
Iron & 19 & 86 & 4 & \\
\hline
\end{tabular}

A comparison of these results with those obtained for coarser particles ${ }^{1}$ is given in Table 4. The stated improvement (reduction) of the grade is the relative increase (decrease) of the grade in the (non)-mags compared to the feed. In case of the coarser particles the nonmags were retreated five times starting from batches of $15 \mathrm{~g}$ per $500 \mathrm{ml}$ water. Here the nonmags were re- 
treated only twice starting from batches of $5 \mathrm{~g}$ per $250 \mathrm{ml}$. It can be seen that, although the improvement of the grade of the magnetic minerals remains the same, their recovery decreases slightly for smaller particles. Nevertheless there is a considerable decrease of their grade in the nonmags. This leads to a higher grade and recovery of the copper in the mags and a lower grade in the nonmags. The reason for this is the reduction of mechanical trapping, which is clearly demonstrated by the increase of the grade and recovery of the non-magnetic minerals and especially gangue in the nonmags.

TABLE 4

\begin{tabular}{rrrrrr}
\hline \multicolumn{2}{l}{$\begin{array}{l}\text { Improvement } \\
\text { Grade in \% }\end{array}$} & \multicolumn{3}{c}{ Recovery in \% } \\
\hline \multicolumn{3}{c}{ Particle Size } & Fractions in $\mu \mathrm{m}$ \\
\hline $53-75$ & $38-53$ & $5-38$ & $53-75$ & $38-53$ & $5-38$ \\
& & & & & \\
\hline 20 & 20 & 20 & 90 & 87 & 82 \\
5 & 15 & 50 & 85 & 85 & 88 \\
25 & 0 & 60 & 27 & 40 & 60 \\
65 & 80 & 185 & 44 & 57 & 83 \\
\hline
\end{tabular}

Reduction Grade in \%

Magn. Mineral in Mags Copper in Mags

Non Magn. Min. in Non Mags Gangue in Non Mags

$\begin{array}{lllr}\text { Magn. Min. in Non Mags } & 25 & 40 & 180 \\ \text { Copper in Non Mags } & 35 & 40 & 70\end{array}$

TABLE 5 Results Copper Ore

\begin{tabular}{lcccc}
\hline \multirow{2}{*}{ Minerals } & \multicolumn{2}{c}{ MAGS $25 \%$ of feed } & NON MAGS & 75\% of feed \\
\cline { 2 - 5 } & Grade \% & Recovery \% & Grade \% & Recovery \% \\
\hline Chalcopyrite & 12 & 58 & 3 & 42 \\
Bornite & 32 & 79 & 3 & 21 \\
$\begin{array}{l}\text { Pyrite + Carrollite }+ \\
\quad \text { Calcocite }\end{array}$ & 3 & 17 & 5 & 83 \\
Strong Mags & 5 & 100 & & 84 \\
Gangue & 49 & 16 & 89 & 42 \\
\hline Copper & 9 & 58 & 2 & 41 \\
Iron & 7 & 59 & 2 & \\
\hline
\end{tabular}


The results obtained on the copper ore are presented in Table 5. The recovery of bornite and chalcopyrite in the mags (together $72 \%$ ) is reasonable. Although their grade in the mags is not very high, the increase of the grade (175\%) is quite good. The copper recovery is low because about half the copper in the nonmags is present in the high copper bearing $(80 \% \mathrm{Cu})$ and diamagnetic chalcocite ( $4 \%$ in the nonmags). No comparison is made with the coarser particle size fraction, because there is too much intergrowth in those fractions.

\section{CONCLUSIONS}

Even at a magnetic background field of $1.3 \mathrm{~T}$ an effective magnetic separation of small bornite and chalcopyrite particles (5-38 $\mu \mathrm{m})$ can be achieved. For larger particles the performance of the magnetic separation can be improved by the use of less dense or coarser matrices. This was also demonstrated by El Tawil etal ${ }^{2}$. The number of times the nonmags have to be retreated in order to increase the recovery of especially chalcopyrite can be reduced by avoiding the feeding of a saturated filter. This will also lad to a higher grade in the mags. The concentration of bornite and chalcopyrite from low grade feeds by High Gradient Magnetic Separation (HGMS) will improve by applying HGMS at higher magnetic fields $(\cong 2 \mathrm{~T})$ and retreatment of the mags at lower fields.

\section{ACKNOWLEDGEMENTS}

The authors wish to thank the Netherlands University Foundation for International Cooperation for their financial support and the Zambian Mining Industrial Technical Service for the provision of samples. The authors would also like to thank Mr. D. Wazili for his work on the separation.

\section{REFERENCES}

1. J.N.M. Agricola, J.L. Top and A.F. Fort, Magnetic Separation of Weakly Magnetic Copper Minerals, IEEE Trans. Magn. 21, 2065 (1985).

2. M.M. El Tawil and M.M. Morales, Application of Wet High Intensity Magnetic Separation to Sulfide Mineral Benefication, presented at the International Symposium on Complex Sulfides, 1985.

* Present address: Department of Applied Physics. Twente University of Technology, P.O.B. 217, 7500 AE Enschede, The Netherlands. 